\title{
A Sensitive and Selective Chromogenic Organic Reagent Diacetylmonoxime-3-amino-4-hydroxy Benzoyl Hydrazone Used for Direct and Derivative Spectrophotometric Determination of Copper(II)
}

\author{
B. N.NAGALAKSHMI ${ }^{1}$, C. VISWANATHA ${ }^{2}$, \\ N. DONAPPA ${ }^{3}$ and K. B. CHANDRASEKHAR ${ }^{4}$ \\ ${ }^{1}$ Department of Chemistry, MLA College for women, Bangalore, India \\ ${ }^{2}$ Department of Chemistry, Arba Minch University, Ethiopia \\ ${ }^{3}$ Department of Chemistry, MLA College for women, Bangalore, India \\ ${ }^{4}$ Department of Chemistry JNTUA-OTRI, Ananthapur, A.P, India \\ viswajntu@gmail.com
}

Received 27 February 2015 / Accepted 18 March 2015

\begin{abstract}
Diacetylmonoxime-3-amino-4-hydroxy benzoyl hydrazone (DMAHBH) was used as a novel chromogenic organic reagent for the determination of copper(II) by spectrophotometry. The novel chromogenic organic reagent diacetylmonoxime-3-amino-4-hydroxy benzoyl hydrazone (DMAHBH) gave bright yellow coloured water soluble complex with $\mathrm{Cu}$ (II) in basic buffer ( $\mathrm{pH}$ 8.010.0) medium. The colour complex shows maximum absorbance at $412 \mathrm{~nm}$. The system obeyed Beer's law in the concentration range of 0.3178 to $3.813 \mu \mathrm{g} / \mathrm{mL}$. The optimum copper(II) concentration range for accurate determination as evaluated from Ringbom's plot was 0.6355 to $3.4953 \mu \mathrm{g} / \mathrm{mL}$. The molar absorptivity and Sandell's sensitivity were $1.65 \times 10^{4} \mathrm{~L} \cdot \mathrm{mol}^{-1} \mathrm{~cm}^{-1}$ and $0.00606 \mu \mathrm{g} / \mathrm{cm}^{2}$ respectively. The copper(II) forms M:L (I:I) colour complex with DMAHBH and stability constant of the complex was found to be. $7.15 \times 10^{5}$. This developed method was applied for the determination of copper(II) in food samples like vegetables and milk samples and obtained with good results compared with reference AAS results.
\end{abstract}

Keywords: Novel chromogenic organic reagent, Derivative spectrophotometry, $\mathrm{Cu}(\mathrm{II})$ and Food samples, Milk samples

\section{Introduction}

Copper is available in nature in the free state in the form of sulphides, chlorides and carbonates. Copper is utilized in electrical industries, electronic industries and industrially useful alloys. It is widely used in printed circuit boards, generators, transformers, computer 
heat sinks, coins. Because of its biostatic property it is used as roofing material for houses. Copper knobs are used in hospitals to reduce the transfer of disease.

Copper is essential for all plants and animals. It is an essential constituent of about thirty enzymes and glycoprotein and is required for the synthesis of hemoglobin and for some biological processes. It also promotes iron absorption from the gastrointestinal system, is involved in the transport of Iron from tissues in to plasma, helps to maintain myelin in the nervous system, and is important in the formation of bone and brain tissues. A deficiency of copper causes diseases such as anemia.

Though copper is an essential element, it becomes hazardous when present in excess. Excess of copper causes jaundice and Wilson disease. Excess of copper in water is not only harmful to human beings, but also interferes with the self-purification of bulk water and exerts an adverse effect on the microbiological treatment of waste water. Too much copper in water has also been found to damage marine life.

A vast number of organic reagents were reported for the spectrophotometric determination of the copper ion. The author has therefore not ventured to describe all these reagents in view of the fact that good reference books ${ }^{1,2}$ are available on this topic.

A number of chromogenic organic reagents were reported for the spectrophotometric determination $^{3-20}$ of the copper ion. For the determination of copper at micro levels, several frequently adopted methods and analytical techniques such as AAS, ICP-AES, X-Ray fluorescence spectroscopy, voltammetry, polarography and spectrophotometry were adopted $^{21-24}$ and among them, spectrophotometric methods are preferred because they are low cost instrument and high sensitivity.

\section{Experimental}

Spectrophotometric measurements were made in a Shimadzu 160 a microcomputer based UV-Visible spectrophotometer equipped with $1.0 \mathrm{~cm}$ quartz cells, an ELICO LI- 120 digital $\mathrm{pH}$ meter. All reagents used were of analytical reagent (AR) grade unless otherwise stated. All solutions were prepared with distilled water

The structure of reagent is confirmed by IR, NMR and Mass spectroscopy

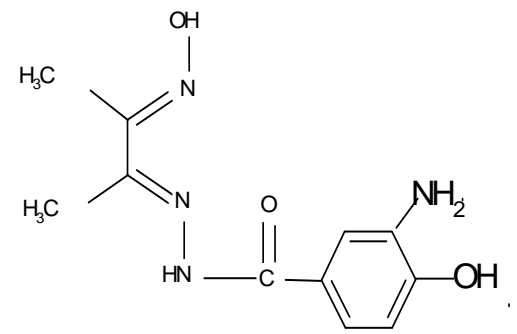

Figure 1. Diacetylmonoxime-3-amino-4-hydroxy benzoyl hydrazone

\section{Analytical properties of DMAHBH}

The reactions of some important metal ions were tested at different $\mathrm{pH}$ values. The samples

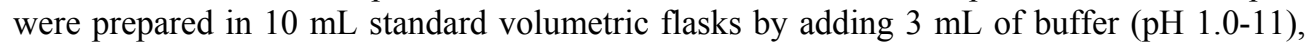
$0.5 \mathrm{~mL}$ of metal ion $\left(1 \times 10^{-3} \mathrm{M}\right)$ and $0.5 \mathrm{~mL}$ of $\left(1 \times 10^{-2} \mathrm{M}\right)$ DMAHBH solutions. The solution mixture was diluted up to the mark with distilled water. The absorbance was measured in 300-800 nm range against reagent blank. 


\section{Recommended procedure}

\section{Determination of copper(II) (zero order)}

An aliquot of the solution containing 0.3178 to $3.813 \mu \mathrm{g} / \mathrm{mL}$ of copper(II), $3 \mathrm{~mL}$ of buffer solution $\mathrm{pH} 8.0$ to 10.0 and $0.5 \mathrm{~mL}$ of $\left(1 \times 10^{-2} \mathrm{M}\right)$ DMAHBH reagent were taken in a $10 \mathrm{~mL}$ standard volumetric flask and the solution was diluted up to the mark with distilled water. The absorbance of the solution was recorded at $412 \mathrm{~nm}$ in a $1.0 \mathrm{~cm}$ cell again corresponding reagent blank prepared in the same way but without copper(II) metal solution. The absorption spectra of DMAHBH and its $\mathrm{Cu}$ (II) complex under the optimum conditions are shown in Figure 2. The $\mathrm{Cu}(\mathrm{II})-\mathrm{DMAHBH}$ complex shows the maximum absorbance at $412 \mathrm{~nm}$, where as the reagent blank does not absorb appreciably.

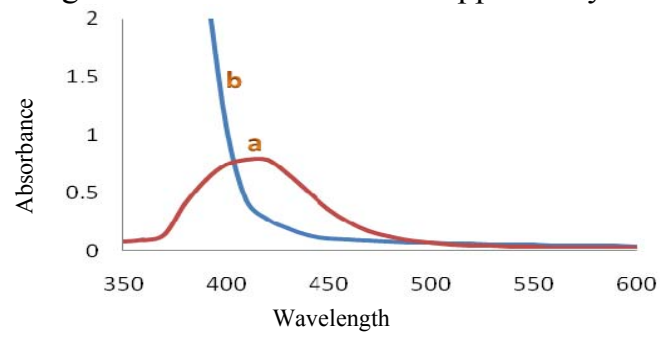

Figure 2. Absorption spectra (a) [Cu(II)-DMAHBH] complex vs. reagent blank (b) DMAHBH vs. buffer blank

\section{Results and Discussion}

Diacetylmonoxime-3-amino-4-hydroxy benzoyl hydrazone (DMAHBH) reagent is a blend of a carbonyl compound and a hydrazide. The reagent solution is stable for more then $24 \mathrm{~h}$. in presence of buffer medium. The ligand presumably coordinates the metal ions to give a neutral water soluble complex.

\section{Determination of Copper(II) using DMAHBH}

Copper(II) reacts with DMAHBH in acidic medium to give bright yellow coloured watersoluble complex. The colour reaction between copper(II) and DMAHBH are instantaneous even at room temperature in the $\mathrm{pH}$ range 8.0 to 10.0. The absorbance of the bright yellow coloured species remains constant for five hours. The maximum colour intensity is observed at $\mathrm{pH}$ 9.0. A 10-fold molar excess of reagent is adequate for full colour development. The order of addition of buffer solution, metal ion and reagent has no adverse effect on the absorbance. The complex formation reaction between copper(II) and DMAHBH has been studied in detail based on the composition of the complex as determined by using Job's and molar ratio methods. Important physicochemical and analytical characteristics of copper(II) and DMAHBH are summarized in Table 1.

Table 1. Physicochemical and analytical characteristics of [Cu(II)-DMAHBH] complex

\begin{tabular}{|c|c|}
\hline Characteristics & Results \\
\hline Colour & Bright yellow \\
\hline$\lambda_{\max }, \mathrm{nm}$ & 412 \\
\hline pH range (optimum) & $8.0-10.0$ \\
\hline $\begin{array}{l}\text { Mole of reagent required per mole of metal ion for full } \\
\text { colour development }\end{array}$ & 10 folds \\
\hline
\end{tabular}


Molar absorptivity, L.mol ${ }^{-1} \mathrm{~cm}^{-1}(\varepsilon)$

Sandell's sensitivity, $\mu \mathrm{g} / \mathrm{cm}^{2}$

Beer's law validity range, $\mu \mathrm{g} / \mathrm{mL}$

Optimum concentration range, $\mu \mathrm{g} / \mathrm{mL}$

Composition of complex(M:L) obtained in Job's and mole ratio methods

Stability constant of the complex

Standard deviation

Relative standard deviation, $\%$
$1.65 \times 10^{4}$

0.00606

$0.3178-3.813$

$0.6355-3.4953$

$1: 1$

The system $\mathrm{Cu}(\mathrm{II})-\mathrm{DMAHBH}$ obeys beers law and the calibrated values were presented in Figure 3.

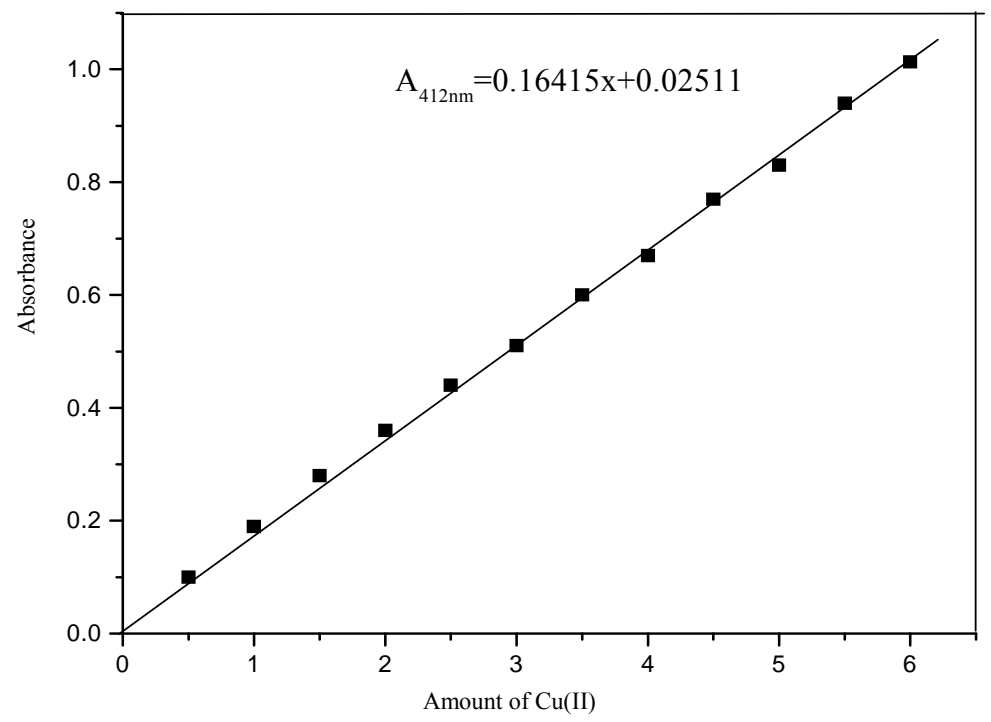

Figure 3. Absorbance vs. Amount of $\mathrm{Cu}(\mathrm{II}) \mu \mathrm{g} / \mathrm{mL}[\mathrm{DMAHBH}]=1 \times 10^{-2} \mathrm{pH}=9.0$ Wavelength $=412 \mathrm{~nm}$

The first order derivative spectral graph was shown in Figure 4. This shows that the derivative amplitudes measured at $466 \mathrm{~nm}$. First order was found to be proportional to the amount of copper(II) respectively.

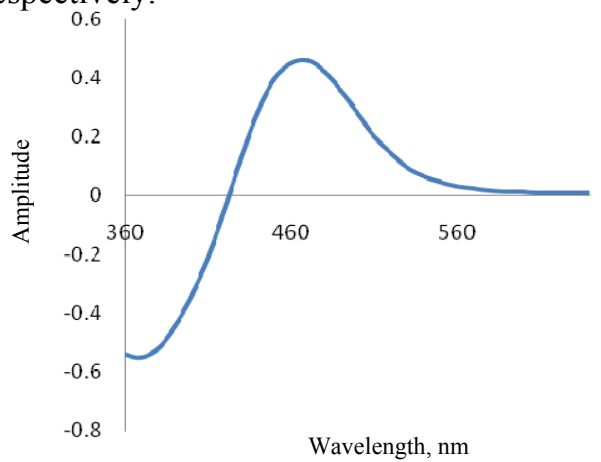

Figure 4. First derivative spectra of [Cu(II)-DMAHBH] vs. reagent 


\section{Effect of foreign ions}

Derivative spectrophotometry is a very useful technique in the sense that it decreases the interference, i.e., increases the tolerance limit value of foreign ions of metal ions having overlapping spectra. The recommended procedures have been employed for the spectrophotometric determination of copper(II). The effect of various diverse ions in the determination of copper(II) was studied to find out the tolerance limit of foreign ions in the present method. The tolerance limit of a foreign ion was taken as the amount of foreign ion required to cause an error of $\pm 2 \%$ in the absorbance or amplitude. The results are given in Table 3.

Table 2. Tolerance limit of foreign ions in the determination of $1.5888 \mu \mathrm{g} / \mathrm{mL}$ of copper(II)

\begin{tabular}{cccc}
\hline Ion added & Tolerance limit, $\mu \mathrm{g} / \mathrm{mL}$ & Ion added & Tolerance limit, $\mu \mathrm{g} / \mathrm{mL}$ \\
\hline Sulphate & 144 & $\mathrm{Ba}^{2+}$ & 20 \\
Phosphate & 133 & $\mathrm{Sb}^{3+}$ & 18 \\
Citrate & 112 & $\mathrm{Se}^{3+}$ & 11 \\
Tartarate & 110 & $\mathrm{Ni}^{2+}$ & 11 \\
Nitrate & 62 & $\mathrm{Zn}^{2+}$ & 6.0 \\
Acetate & 56 & $\mathrm{Sn}^{2+}$ & 6.0 \\
Fluoride & 37 & $\mathrm{~W}^{6+}$ & 4.0 \\
Chloride & 35 & $\mathrm{Fe}^{3+}$ & $2,6^{\mathrm{a}}$ \\
Tetraborate & 33 & $\mathrm{Co}^{2+}$ & $1,3^{\mathrm{b}}$ \\
Bromide & 8.0 & $\mathrm{Cd}^{2+}$ & 1.0 \\
Ascorbic acid & 1.0 & $\mathrm{Al}^{2+}$ & 1.0 \\
\hline
\end{tabular}

${ }^{a}$ Masked with $49 \mu \mathrm{g} / \mathrm{mL}$ of fluoride, ${ }^{b}$ Masked by $76 \mu \mathrm{g} / \mathrm{mL}$ of triethanolamine

\section{Applications}

\section{Determination of copper(II) in food sample}

The content of copper(II) present in the solution was determined by using the recommended procedure and the results obtained were confirmed by direct AAS method (Atomic absorption spectrophotometry). The results obtained are presented in Table 3.

Table 3. Determination of copper(II) in food samples

\begin{tabular}{cccc}
\hline \multirow{2}{*}{ Sample } & \multicolumn{2}{c}{ Amount of copper(II) $\mu \mathrm{g} / \mathrm{g}$} & \multirow{2}{*}{ Error \% } \\
\cline { 2 - 3 } & AAS method & Present method* & \\
\hline Amaranthus & 15.45 & 15.32 & 0.841 \\
Gangeticus(Thotakura) & 5.00 & 4.92 & 1.60 \\
Cow milk & 4.25 & 4.23 & 0.471 \\
Dairy milk & &
\end{tabular}

*Average of the best three determinations among five determinations

\section{Conclusion}

In basic medium, the Diacetylmonoxime-3-amino-4-hydroxy benzoyl hydrazone (DMAHBH) reacts with copper(II) and imparts bright yellow colouration water soluble complex. The colour reaction between copper(II) and DMAHBH is instantaneous and the absorbance of the coloured species remains constant for $5 \mathrm{~h}$. Order of addition of constituents (buffer, metal ion and reagent) has no adverse effect on the absorbance of the complex. 
Diacetylmonoxime-3-amino-4-hydroxy benzoyl hydrazone (DMAHBH) has been proven a sensitive and selective chromogenic organic reagent for the determination of copper(II). Molar absorptivity of the colour complex was $1.65 \times 104 \mathrm{~L} . \mathrm{mole}^{-1} \mathrm{~cm}^{-1}$. The proposed method was especially sensitive and selective with respect to metals, which commonly seriously interfere with the determination of copper performed by literature methods. The proposed method can be successfully applied to the determination of copper(II) in food samples. This method was favorably compared with previously reported spectrophotometric ${ }^{1-20}$ methods.

\section{Acknowledgement}

The authors are thankful to the Jawaharlal Nehru Technological University, Anantapur, Anthapuramu, A.P, India, for providing research facilities to carry out my present work.

\section{References}

1. Garcia R M, Alvarez M L B, Fernandez M T F, Garcia M J A and Anales D E, Quimica, 1991, 87(5), 626.

2. Issa Y M, Rizk M S, Mohamad H A and Mohamad S J, J Indian Chem Soc., 1992, 74, 128.

3. Kalani, Rekha and Mathur S P, Chem Environ Res., 1993, 2(3-4), 301.

4. Zhu Y, Liu J, Liu P and Zhou X, Mikro Chimica Acta., 1993, 112(1-4), 127-133; DOI:10.1007/BF01243329

5. $\quad$ Furukawa M, Katami T, Shibata S and Fresenius, J Anal Chem., 1993, 347(10-11), 462.

6. Paria P K, Sarkar A and Majumdar S K, J Indian Chem Soc., 1993, 70, 83.

7. Shukla N, Pandey G J and Maitra J K, J Indian Chem Soc., 1993, 70, 793.

8. Abubakr M S, Khalit M M, Sedaira H and Hashem E Y, Indian J Chem., 1994, 33(7)A, 644.

9. Rajput N, Kadam V and Devi S, Indian Chem., 1994, 33A, 88.

10. Maheswari V and Balasubramanian N, Analusis, 1995, 23(8), 412.

11. Talati J D, Parikh K S and Patel P K, J Indian Chem Soc., 1995, 72(10), 749.

12. Bati-B, Cesurn H, Bati H, Ozolemir M, Turk J Chem., 1995, 19(1), 66.

13. Jadhav V A and Vandre AG, J Indian Chem Soc, 1995, 72, 747.

14. Talati J D, Parikh K S and Patel P K, J Indian Chem Soc., 1995, 72(10), 749.

15. Ma H M, Huang Y X and Liong S C, Anal Chim Acta, 1996, 334(1-2), 213-219; DOI:10.1016/S0003-2670(96)00262-0

16. Blazys I, Jurevicius R, Vanilavicius P and Burbulieve M M, Chemija, 1996, 4, 53.

17. Issa Y M, Mohamed H A, Rizk M S and Mohamed S I, Egypt J Anal Chem., 1996, 5, 1.

18. Khader A M A and Prasad K S, Acta Cienc Indica Chem., 1996, 22(3), 61.

19. Balaji T and Naidu G R K, Pollut Res., 1996, 15(3), 311.

20. Ohno S, Teshima N, Watanobe T, Itabashi H, Nakano S and Kawashima T, Analyst, 121(10), 1515-1518; DOI:10.1039/AN9962101515

21. Chimpalee N, Chimpolee D, Lohwithee S, Nakwachara L and Burns Thorburn D, Anal Chim Acta, 1996, 329(3), 315-318; DOI:10.1016/0003-2670(96)00141-9

22. Issa Y M, Omar M M, Rizk M S and Mohamed S E, Indian J Chem., 1996, 35A(B), 718.

23. Sharma K and Patel K S, J Indian Chem Soc., 1996, 73(8), 443.

24. Priyadarshini S S and Dhadke P M, Indian J Chem Technol., 1996, 3(6), 367-370. 